Est Ag 38 (2003) 147-151

\title{
La metafísica del Uno y las Enéadas de Plotino
}

En la metafísica de las Enéadas la omnipresencia del Uno es un tema fundamental. Porfirio en su edición de las Enéadas insertó en la Enéada sexta dos tratados muy extensos sobre este tema: Enn. VI 4 y Enn. VI 5. La estructura de los argumentos desarrollados en estos dos tratados, que son cronológicamente el 22 y el 23, corresponde con su puesto dentro de la cronología como nos la da Porfirio. Fueron escritos por Plotino en el período en que Porfirio, llegado a Roma, tomaba porte en los debates. En la argumentación minuciosa se reconoce el estilo de investigaciones y discusiones habidas en la escuela, y puestas por escrito a instancia de Amelio y Porfirio (Vita, 5).

En el comienzo de Enn. VI 4 (22) cap. 1 el problema se formula así: ¿es que el alma se encuentra por doquier en el universo?; ¿es ella, consecuentemente, de dimensión idéntica a la del cuerpo del universo? No se puede decir que el alma se divida según los cuerpos, porque en este caso el alma sufriría divisiones en detrimento de su propia existencia. Muy al contrario, el alma ya

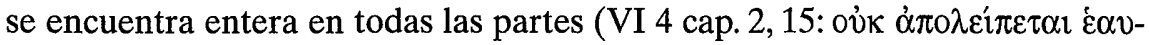
$\tau 0 \widetilde{v})$, y dondequiera se ponga el cuerpo, el cuerpo encuentra el alma. La exis-

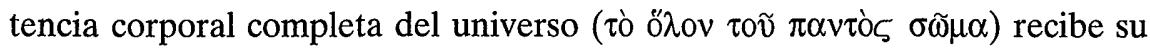
sitio dentro de un alma ya anteriormente existente. $Y_{\text {¿cómo conseguiría el }}$

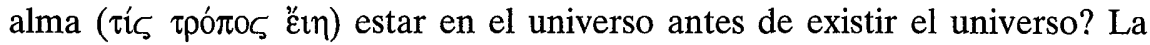
conclusión inevitable del argumento es que, para el alma, tener dimensión es un concepto incompatible con tener existencia como alma del universo.

Los varios capítulos de Enn. VI 4 (22) están redactados de una manera teórica y conceptual, parece ser que con vistas a lo que va a ser expuesto en Enn. VI 5 (23). El concepto de la omnipresencia del alma se desarrolla a fondo en Enn. VI 4 como preludio y ejercicio preliminar para la teoría metafísica del Uno. El Uno está presente en todos los seres, sin que por eso sufra detrimento en su unidad.

Plotino toma como ejemplo la percepción visual y auditiva. En el acto de la visión una imagen del objeto es captada por el ojo y se comunica a muchos ojos en forma idéntica (VI 4, cap. 12,49). En cierto sentido se puede decir que esta imagen es omnipresente $(12,32)$. Así también una palabra hablada se 
manifiesta por todo el espacio en forma idéntica (cap. 12, 16-18: $\pi \alpha v \tau \alpha \chi 0 \widetilde{v}$

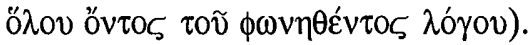

La omnipresencia del Uno no perjudica al ser todo de este primer principio. Estando presente el Uno con su poder creativo en la infinidad de los seres, no les depara partes de sí mismo, lo que implicaría que el Uno no podría mantener su Unidad. La fórmula ya se encuentra en VI 4, cap. 2, 15, sólo que aquí lo que vale para el Uno se formula con el término tò $\pi \widetilde{\alpha} v$ : el universo no puede faltar a sí mismo. A este texto se alude en el exordio de VI 5 (23) 1,1-4: que el uno y lo mismo está en todas partes y en su totalidad, se afirma por una

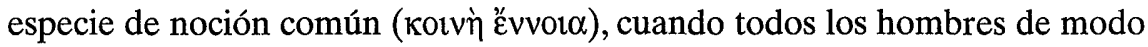
espontáneo (o digamos arquetípico) indican al Dios que en cada uno de nosotros está presente como el único e idéntico (cap. 1,1-4).

En una nota a pie de página de su edición del texto en la serie Loeb (tomo VI, p. 326), Armstrong advierte: "Es este uno de los muy poco frecuentes recursos de Plotino a una noción común que pueda ser base de una investigación filosófica". La omnipresencia del ser es una noción común (Korvì ع̌vvor $\alpha$ en el idioma estoico) espontáneamente admitido por todos los hombres (VI 5, cap. 1). En terminología moderna sería una "noción arquetípica", transmitida por herencia a todos los hombres que lo harían constar así basándose en su entendimiento. Se fundarían en la noción del uno e idéntico y rehusarían distanciarse de esta unidad. Este principio es el más sólido de todos $(\beta \varepsilon \beta \alpha$ ió $\tau \alpha \tau o v$, cap. 1,9$)$ y reside como en el aliento de nuestras almas, porque no es un resumen de observaciones particulares, y se presenta ante-

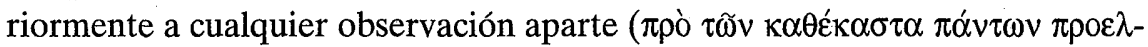
өoṽ $\sigma$, cap. 1, 10-1 1).

El argumento se repite varias veces en VI 5, cap. 4: "Mantenemos firme que Dios no puede estar en cierto lugar sí y en otro no. Es admitido por todos los que tienen una noción ( $\left({ }^{\prime} v v o t \alpha v\right)$ de los dioses, no tan sólo de este Dios

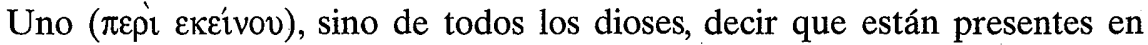
todas partes (cap. 4, 4). También la lógica (o $\lambda$ ó$_{0} \sigma_{5}$ ) dice que hay que plantearlo así. Aun estando el Uno en todas partes, no es posible que esté dividido, porque en este caso no seria Él, que se encontraría por todas partes, sino que estarían sus fragmentos el uno aquí y el otro allí, y Él mismo no seguiría siendo Uno, como si una magnitud fuera desgarrada en múltiples elementos. En ese caso el Uno mismo cesaría de existir como tal, y la suma de las partes ya no constituiría la unidad completa. Además él tendría la naturaleza de un cuerpo (VI 5, cap. 4, 1-10).

$\mathrm{El}$ argumento es una versión ampliada de lo que hemos leído en VI 4, cap. 2, 15; el Uno no se separa de sí mismo, y aun estando presente en las cosas, no se introduce en las cosas para formar parte de ellas (VI 5, cap. 10, 
1-3: "El Uno se mantiene en el dominio de sí mismo ( $\sigma \omega \phi \rho \circ v o v ̃ v)$ y no puede entrar en otra cosa".

Encontramos esta afirmación ya en los tratados cronológicamente primeros. En VI 9 (9) cap. 7, 25-30 leemos: "Dios no está ausente de nadie, sino que está presente a todos sin que lo sepan", porque huyen de Él o, mejor dicho, de sí mismos. Esta afirmación corresponde con lo que dice otro tratado temprano (V 1 (10) cap. 1): las almas se olvidan de su propio linaje, se han desgarrado de Dios su Padre. El deseo de reencontrar su propia unidad y entereza primordial es una nostalgia, con todos los rasgos propios de un ena-

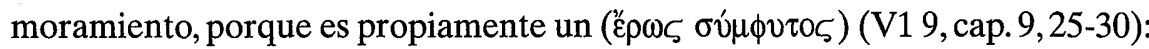
el alma se enamora de su origen por una ley de su propia naturaleza ( $\dot{\varepsilon} \xi$

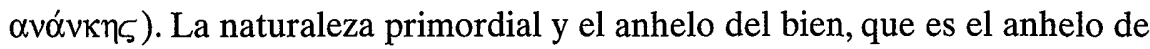
encontrarse a sí misma, la conduce al verdaderamente Uno, y hacia esto se

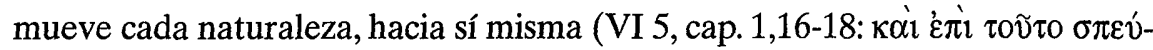

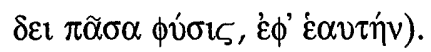

La falta de unidad se origina en el descenso, cuando el alma desciende para tomar parte en la vida de un cuerpo (VI 4, cap. 16). “¿Cuál es, en fin de cuentas, la causa que provoca a las almas a olvidarse de Dios su Padre, y, siendo partes que vienen de Él y que a Él pertenecen, a desconocerse tanto a sí mismas cuanto a Él?". La respuesta viene en el exordio de V 1 (10): Raíz y origen de este mal es la osadía y el engendrar, la diferencia primordial y la ambición de pertenecerse a sí mismas. Deleitándose en esta autodeterminación y teniendo gran libertad para actuar independientemente, iban en dirección contrapuesta y recorrían la mayor distancia posible, desconociendo completamente que su propio origen estaba allí. Eran como niños separados inmediatamente de sus padres y por largo tiempo criados muy lejos de ellos, que no piensan ni en sí mismos ni en sus padres. Perdieron el respeto a sí mismas por ignorancia de su linaje, considerando como valiosas otras cosas, y admirándolas mucho más que a sí mismas. La causa de la completa ignorancia de Dios (દ̌kcívov) reside en la admiración que tienen las almas por las cosas de aquí, y la falta de respeto hacia sí mismas.

Cuando las almas viven dentro de un cuerpo no desaparece por completo la percepción de la condición en que les es dado vivir. El alma se divide a

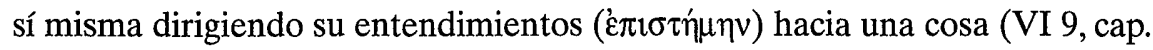
4, 3-50). Entonces abandona la unidad y pasa a la esfera del número y la cantidad. Esto indica que hay que subir por encima del entendimiento y en ningún modo desistir del ser uno. Hay que renunciar al entendimiento ( $\left.\dot{\alpha} \pi \circ \sigma \tau \widetilde{\eta} v \alpha_{\imath} \delta \tilde{\varepsilon} \varepsilon \pi \imath \tau \tau \tilde{\eta} \mu \eta \zeta\right)$ y sus objetos y de cualquier otra representación agradable. 
¿Qué les pasará a las almas una vez se den cuenta de su condición? Se apodera de ellas un deseo irresistible de volver a su origen, es decir a su propia unidad original. Volviendo a su origen divino estará colmada de Dios ( $\pi \lambda \eta \omega \theta \varepsilon \tilde{\sigma} \sigma \alpha \theta \varepsilon 0 \widetilde{v})$; entonces genera belleza, justicia y virtud, y esto es para ella tanto el principio como el fin, porque viene de allí y allí está el bien. Lle-

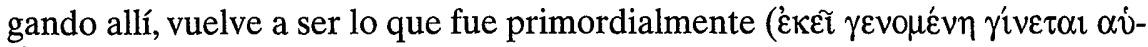

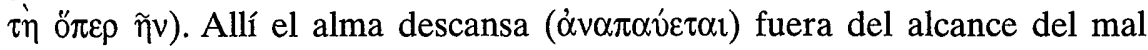

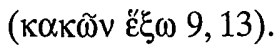

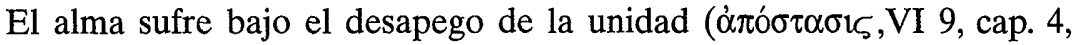
1-10). No es completamente una cuando va tomando conocimiento de otras cosas. El conocimiento de la primera unidad no se realiza como se realiza un argumento componiendo las partes para formar un conjunto lógico, sino a base de una presencia, que es más fuerte que un argumento.

Cuando el alma, dividida en sí misma, se da cuenta de todo esto, entonces se conmueve y se asusta ( $\varepsilon \kappa \pi \lambda \alpha \gamma \varepsilon \tilde{\tau} \sigma \alpha \mathrm{V} 1$, cap. 1,13$)$ y quiere volver a lo

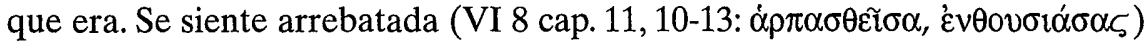
y quiere volver a su verdadera naturaleza, es decir a sí misma (VI 5, cap. 1,1718). Es esto a lo que se apresura cada naturaleza, a sí misma. El impulso del alma a volver a su propia naturaleza toma la forma de un enamoramiento.

El símbolo del enamoramiento tiene sus raíces en la mitología de la escuela de Valentín que describe el mundo entero de los dioses, el Pléroma, según distintos grados de importancia y poder como una amplia familia, que proviene del Padre único y primordial. La última que desciende y que vive al borde del abismo es Sofía, que difícilmente tolera el destierro y la separación del Dios Padre perfecto. Su pasión consiste en la búsqueda del Padre, que en sí misma es enamoramiento, pero en el texto de Ireneo es llamada arrogancia

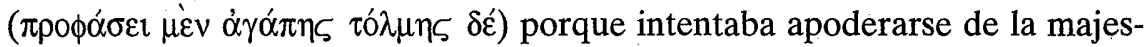
tad del Padre. Era un perseguir lo imposible por la enormidad del abismo y

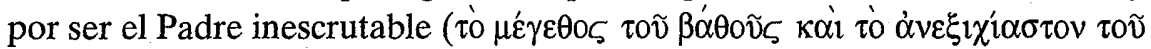
$\left.\Pi \alpha \tau \tilde{o}^{\prime} \varsigma^{1}\right)$. Corría el peligro de ser absorbida y fundida en el resto del universo, y así hubiera sucedido si no se hubiera encontrado con el guardián del universo, un Redentor llamado "Opos. Este guardián alienta a Sofía a convertirse.

En la Enéada sexta encontramos otra vez el tema del enamoramiento (VI 9, cap. 9, 33-37):

1. W.VólKer, Quellen zur Geschichte der christlichen Gnosis, Tübingen 1932, p. 97; W. HARVEY, Sancti Irenaei Libros quinque adversus haereses, Cantabrigiae 1857, I 1, p. 14-15. 


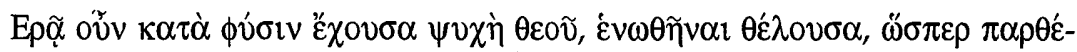

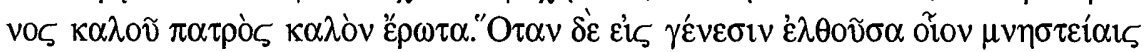

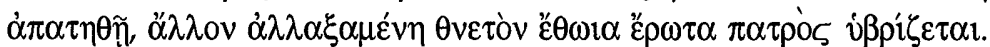

"Cuando el alma sigue la condición de su naturaleza, se enamora de Dios, deseando unirse a Él, igual que una hija de buena estirpe se enamora con sano amor de su padre. Pero cuando el alma viene a parar en la esfera del devenir y se deja seducir por el encanto de los cosas de este mundo ( $\gamma$ ćveotv = la tarea de crear la vida), entonces intercambia el amor del Padre por otro amor mortal y, faltándole el Padre, se siente defraudada y humillada".

En el contexto de estos párrafos eróticos también la expresión $\mu$ óvo

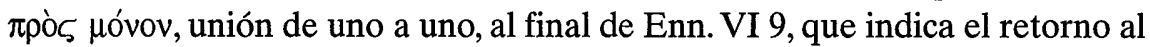
origen, conserva la resonancia del enamoramiento. El enamoramiento de Sofía ha sido transformado y adaptado dentro de la estructura metafísica del principio de unidad. En esta estructura el enamoramiento y el deseo nostálgico de unión con el Dios supremo, son una necesidad metafísica dentro de la teoría del Uno.

DR. Th. G. SINNIGE Jeruzalem 8 6881 JJ Velp Holanda 